Auburn University

Department of Economics

Working Paper Series

A U B URN

U N I V E R S I T Y

\title{
U.S. Presidential Election Polls and the Economic Prospects of China and Mexico
}

Hyeongwoo Kim* and Madeline H. Kim ${ }^{+}$

*Auburn University, ${ }^{\dagger}$ Carnegie Mellon University

AUWP 2020-08

This paper can be downloaded without charge from:

http://cla.auburn.edu/econwp/

http://econpapers.repec.org/paper/abnwpaper/ 


\title{
U.S. Presidential Election Polls and the Economic Prospects of China and Mexico
}

\author{
Hyeongwoo Kim* and Madeline $\mathrm{H} . \mathrm{Kim}^{\dagger}$
}

November 2020

\begin{abstract}
Motivated by Mr. Trump's agendas against China and Mexico, we investigate how a candidate's probability of winning the U.S. presidential election affects the financial markets that are related to these countries. Unexpected increases in Trump's winning probability in the 2020 election generate significantly negative long-term effects on the home currency and the stock prices, while the default probability responds significantly positively in the long run. Similar responses, though in the short run, were observed when Mr. Biden's probability of winning increases, which dissipates quickly over time. We note that the responses to the Biden shock resemble those to the Trump shock during the 2016 election, implying that the probability shock of the new entrant candidate tends to create short-run disturbances in the financial market, whereas the probability shock of the incumbent candidate such as Trump in 2020 or Clinton in 2016 tends to stabilize financial markets in the short run.
\end{abstract}

Keywords: Donald Trump; Joe Biden; Hillary Clinton; Incumbent Candidate; Predictlt; Financial market

JEL Classification: E44; F31; G15

\footnotetext{
* Department of Economics, College of Liberal Arts, Auburn University, Auburn, AL 36849. Tel: 334.844.2928. Email: gmmkim@gmail.com.

+ Carnegie Mellon University. Student. Email: madelink@andrew.cmu.edu.
} 


\section{Introduction}

Donald Trump built his 2016 presidential campaign on brazen promises, one of the most memorable being a border wall separating the U.S. from Mexico in addition to stringent measures to deter illegal immigration. Mr. Trump also had promised to renegotiate the North American Free Trade Agreement (NAFTA), heavily criticizing it for driving jobs to Mexico. $^{1}$

He maintained a similar hawkish approach to trade when it came to China. Within his first 100 days of presidency, he vowed that the Secretary of Treasury would label China "a currency manipulator" and close the increasing trade deficit between the two countries. He not only maintained this promise but continued his confrontational stance against China. This was demonstrated through tariffs that affected nearly three-quarters of everything that China sells to the U.S. to promising to "bring back jobs" that were "stolen" from American workers.

Such hostile political agendas can be considered as potential economic threats to these countries that have close economic ties to the U.S., implying that the prospect of a Trump presidency may be translated into financial markets that are connected to the economic prospects in these countries. One challenge in empirically investigating such links is measuring the probability of a candidate winning an election. In the current literature, most empirical analyses utilize the contract prices of binary options regarding election outcomes in prediction markets. ${ }^{2}$

Using the lowa Electronic Market (IEM) data, Herron, Lavin, Cram, and Silver (1999) revealed significantly positive correlations between the 1992 U.S. presidential election outcome and expected profits of the sectors that are likely to be favored by a potential

\footnotetext{
${ }^{1}$ Upon election, the Trump administration continued a renegotiation that resulted in the United StatesMexico-Canada Agreement (USMCA) that took effect on July 1, 2020.

${ }^{2}$ Wolfers and Zitzewitz (2006b) provide a theoretical foundation that allows one to interpret prediction market prices as the probability that an event occurs. Wolfers and Zitzewitz (2006a) provide a short literature review on how prediction markets efficiently aggregate disperse information to formulate market forecasts.
} 
winner, Bill Clinton or George H.W. Bush. ${ }^{3}$ For example, they demonstrate that profits of the pollution control sector are expected to be higher if Clinton wins the election, while the opposite is true for expected profits for the pharmaceutical industry sector. Similar firm-specific evidence was obtained by Knight (2006) who employed the IEM for the 2000 U.S. presidential election when George W. Bush and Al Gore fought a close election. Using high frequency financial market data, Snowberg, Wolfers and Zitzewitz (2007) demonstrate how election outcomes substantially affect financial markets such as equity and bond markets as well as exchange rates and oil prices using election polls data in 2000 and 2004.

More recently, Beard, Kim, and Stern (2017) report that Mr. Trump's probability of winning generates short-run, but statistically significant disturbances to the U.S. DollarMexican Peso exchange rate. Wagner, Zeckhauser, and Ziegler (2018) focused on Mr. Trump's tax policy effects, and demonstrate that expected changes in corporate tax policy, via Trump's higher chances of winning the 2016 election, positively impact firm values. Goodell, McGee, and McGroarty (2020) show how the election uncertainty may impact policy uncertainty and financial market uncertainty. Specifically, they show that the incumbent party's re-election probability plays an important role in explaining financial market uncertainty.

We employ the share price data of the recent two U.S. election polls related contracts that are traded in a non-profit trading platform called Predictlt.org, sponsored by Victoria University of Wellington, New Zealand. They provide well-capitalized prediction markets that allow participants to trade in simple binary contracts on a specific event. They place offers to buy or sell contract shares in real-time, which pays $\$ 1$ per share if a specified event occurs (e.g., "Will Donald Trump win the popular vote in 2020?") and pays $\$ 0$ otherwise when the market concludes the associated event. Naturally, the prices of such contracts lie between $\$ 0$ and $\$ 1$. Market participants bid a higher price as their perceived likelihood of the event becomes higher, while lower prices will be settled when the events

\footnotetext{
${ }^{3}$ The IEM was created in 1988 and was initially called the lowa Political Stock Market.
} 
become unlikely to happen. Therefore, the prices of such contracts can be interpreted as market probability assessments of how likely the associated outcome would occur.

We take advantage of the Predictlt daily frequency share prices for the contracts of Mr. Trump and Mr. Biden to study the dynamic effects of the changes in these candidates' respective probabilities of winning on macroeconomic perspectives of China and Mexico. More specifically, employing a recursively identified vector autoregressive (VAR) model, we investigate how the increases in the probability Mr. Trump (or Mr. Biden) is elected President are translated into the financial markets that are closely related to the economies of China and Mexico: (1) the bilateral exchange rates of the Chinese Yuan and the Mexican Peso relative to the U.S. dollar; (2) the sovereign default probability of these countries based on the credit default swap (CDS) spreads; and (3) the stock market indices of China and Mexico. We extend our analysis using a similar set of data during the 2016 U.S. presidential election when Mrs. Hillary Clinton and Mr. Trump were the candidates.

Our major findings are as follows. In response to an unexpected increase in Mr. Trump's winning probability, the Chinese Yuan and the Mexican Peso depreciate significantly in the long run. The default probabilities of both China and Mexico increase significantly in the long run when the shock occurs. We observe similar responses of these variables but in the short run when Mr. Biden's probability of winning increases unexpectedly, which then dissipate quickly over time. Interestingly, similar short-lived responses can be found to the Trump probability shock during the 2016 election when he was also the new entrant candidate. Responses to the Clinton probability shock were also short-lived, but they implied more stabilizing effects on the financial market possibly because she was the incumbent party's candidate.

It should be noted that the stock market responds positively on impact when the shock occurs to the incumbent candidate's probability: Mr. Trump in 2020 and Mrs. Clinton in 2016. Being consistent with this, the default probability initially declines for both countries in response to these shocks. That is, the probability shock of the incumbent candidate seems to stabilize financial markets in the short run, possibly reflecting a lower 
probability of policy discontinuity, although these initial responses are eventually dominated by harmful longer-term effects on these countries.

We also note that the Mexican stock market becomes bullish in the long run in response to the Trump shock for the 2016 election sample period, which might be due to the expenditure switching effect caused by the depreciation of the Peso. It is interesting to see why we do not observe such improvement in the Mexican stock market when the shock occurs, either to Trump or to Biden, for the 2020 election sample period even though the Peso responds mostly negatively. We interpret this puzzling finding as follows. During Mr. Trump's first term, market participants have observed extremely tough hawkish foreign and trade policies that created substantial (non-price) trade barriers, leading to a weaker role of the expenditure switching effect via the changes in the exchange rate.

The rest of the paper is organized as follows. Section II describes the data used in the paper. We also explain our VAR procedure, which is robust to alternative ordering as we employ a partial identification scheme. In Section III, we report and interpret our major findings. Section IV concludes.

\section{Data and Empirical Strategies}

\section{Data Descriptions}

To measure the probability of winning the election, we employ the close share price of a contract as traded on Predictlt.org. ${ }^{4}$ Observations are daily frequency and span from September 27, 2017 to September 18, 2020, excluding weekends (5 days a week) to match the availability of other financial market data. As mentioned early, the prices of such binary contracts lie between $\$ 0$ and $\$ 1$, which represent the probability assessments of the likelihood of the associated events. For example, a closing price of $\$ 0.40$ of a Trump

\footnotetext{
${ }^{4}$ We obtained the data from the research team of Predictlt.org at research@predictit.org.
} 
presidency contract implies that Mr. Trump's probability of winning is evaluated to be $40 \%$ in the market. Mr. Biden's probability of winning data was obtained from the same source. We also utilize similar daily frequency probability data of Mrs. Clinton and Mr. Trump during the 2016 U.S. presidential election campaign from June 16, 2015 to October 14, 2016.

We obtained daily frequency exchange rate data from the Federal Reserve Economic Data (FRED) for the same sample period as the probability data. The value of the Chinese Yuan and the Mexican Peso, in terms of the U.S. Dollar, is calculated by taking the inverse of the bilateral exchange rates of dollars, DEXCHUS and DEXMXUS, respectively. We also employ the Trade Weighted U.S. Dollar Index relative to a broad range of currencies (DTWEXBGS) for our VAR system to control the factors that influence the overall dynamics of the Dollar exchange rate. The daily Chinese and Mexican stock market indices denominated in local currency are obtained from the Morgan Stanley Capital International, $\mathrm{CH} 50$ (MSCl-China), and $\mathrm{MXMSCl}$ (MSCl-Mexico), respectively. The exchange rates and stock market indices are log-transformed.

We are particularly interested in how the changes in Mr. Trump's (or other candidates') probability to win the election would influence the macroeconomic perspectives of these countries in the associated financial markets. In the absence of highfrequency (daily) macroeconomic variables, we employ the sovereign default probability data based on the credit default swap (CDS) spreads on 1-year sovereign bonds of China and Mexico, assuming that market participants respond to the CDS based on their expectations of the macroeconomic performance conditional on their prospects on the U.S. presidency in the future. The CDS spreads $\left(S P R D_{t}\right)$ are obtained from the Bloomberg Terminal. We calculated the sovereign default probability $\left(D E F P_{t}\right)$ by the following zero profit condition.

$$
S P R D_{t}=(1-R e c v) \times D E F P_{t}
$$

where we assume a $40 \%$ recovery rate $(\operatorname{Recv})$. 
Our raw data series during the 2020 campaign appears in Figure 1 . We pay special attention to the dynamics in the market odds on Trump's election as well as Biden's projected presidency. Mr. Trump's probability of winning began rising rapidly since February 2019 when he received undivided support from the Republican National Committee (RNC). His odds, however, started falling around February 29, 2020, when Mr. Biden won a landslide victory in the 2020 South Carolina Democratic Primary, which reinvigorated his presidential campaign. Reflecting this, Biden's probability rapidly increases since then, eventually surpassing Trump's probability. In March 2020, ten of Biden's former competitors endorsed him, making him the de facto Democratic nominee for president.

We note that China's sovereign default probability is substantially lower than that of Mexico, ranging from $0.04 \%$ to $0.32 \%$, while Mexico's default probability is overall higher than $0.5 \%$ during our sample period. It should be also noted that Mexico experienced a drastically bearish stock market from late February to March 2020 due to the Covid-19 pandemic, which also resulted in rapid depreciation of the Mexican Peso during the same period. It is interesting to observe that the Chinese Yuan has exhibited an overall downward trend during Mr. Trump's presidency since 2017, possibly reflecting exacerbated trade tensions between the U.S. and China regarding trade issues.

\section{Figure 1 somewhere here}

\section{Empirical Methodologies}

Our empirical approach utilizes a recursively identified vector autoregression (VAR) model. Abstracting from deterministic terms, we employ the following $\operatorname{VAR}(p)$,

$$
\mathbf{y}_{t}=\sum_{j=1}^{p} \mathbf{A}_{j} \mathbf{y}_{t-j}+\mathbf{C} \mathbf{u}_{t}
$$


where $\mathbf{y}_{t}=\left[W I N P_{t}, \mathbf{z}_{t}\right]^{\prime}$ is a $5 \times 1$ vector of variables of interest. $W I N P_{t}$ denotes Mr. Trump's or Biden's probability of winning, while $\mathbf{z}_{t}=\left[F O R X_{t}, S T C K_{t}, D E F P_{t}, T R F X_{t}\right]^{\prime}$ is a $4 \times 1$ vector of covariates that includes the bilateral exchange rate FORX $X_{t}$ (Yuan-USD or the Peso-USD rate), the stock market index $\operatorname{STCK}_{t}$ (MSCl-China or MSCl-Mexico) stock index, the sovereign default probability $D E F P_{t}$, and the trade-weighted U.S. dollar index $T R F X_{t} . \mathbf{C}$ is a lower-triangular matrix that governs the contemporaneous relationship between the variables in $\mathbf{y}_{t} . \mathbf{u}_{t}$ is a vector of orthonormalized structural shocks. That is, $E \mathbf{u}_{t} \mathbf{u}_{t}^{\prime}=\mathbf{I}$, where $\mathbf{I}$ is an identity matrix. We demean and detrend all variables prior to VAR estimations. The $j$-period ahead impulse-response function to the probability $\left(W I N P_{t}\right)$ shock is defined as follows.

$$
\phi(j)=E\left(z_{t+j} \mid u_{W I N P_{t}}=1, \Omega_{t-1}\right)-E\left(z_{t+j} \mid \Omega_{t-1}\right)
$$

where $\Omega_{t-1}$ is the adaptive information set at time $t-1$.

Note that $W I N P_{t}$ is ordered first, because it seems reasonable that the Trump (or Biden) contract prices may influence the financial market variables in $\mathbf{z}_{t}$ contemporaneously, whereas the other variables have limited or no influence on Mr. Trump's prospects within a day. It turns out that $\phi(j)$ are "ordering-free" given the location of $W I N P_{t}$. For details, see Christiano, Eichenbaum, and Evans (1999). ${ }^{5}$

It should be noted that the sovereign default probability $\left(D E F P_{t}\right)$ plays an important role. Unlike $F O R X_{t}, S T C K_{t}$, and $\operatorname{TRFX}_{t}$ that are available at a daily frequency, macroeconomic variables that reflect the potential consequences of changes in the U.S. presidency are often available at a much lower frequency, e.g. monthly or quarterly frequency. In the absence of high frequency macroeconomic data, we use $D E F P_{t}$ inferred from the daily frequency CDS spreads on 1-year sovereign bonds, to assess the market participants' perception on the macroeconomic impacts of the probability shock in China and Mexico. That is, we assume that market participants respond to the CDS based on

\footnotetext{
${ }^{5} \phi(j)$ coincides with the generalized IRF (GIRF) proposed by Pesaran and Shin (1998). See Kim (2013) for critical discussions about the use of the GIRF.
} 
their expectations of the macroeconomic performance given their prospects on the U.S. presidency in the future.

\section{Empirical Results}

\section{Is Good News for Trump Bad News to China and Mexico?}

This section reports our major empirical findings on how unexpected changes in Mr. Trump's probability of winning the 2020 U.S. presidential election ultimately translate into financial markets that are closely related to the two target countries during his presidential campaign, China and Mexico.

We first check the contemporaneous correlations between the variables in $\mathbf{y}_{t}=$ $\left[W I N P_{t}, \mathbf{z}_{t}\right]^{\prime}$. For this purpose, we separated the business cycle components of these variables in $\mathbf{y}_{t}$ by removing their trend components via the Hodrick-Prescott (HP) filter. ${ }^{6}$ As can be seen in the scatter plot diagrams in Figure A1 in the appendix, it is difficult to infer any clear relationships between Trump's probability of winning $\left(W I N P_{t}\right)$ and the other variables in both countries, implying that univariate regression approaches, e.g., $W I N P_{t}=\boldsymbol{\beta}^{\prime} \mathbf{z}_{t}+\varepsilon_{t}$, are not likely to provide any useful statistical inferences. Hence, we shift our attention to dynamic analysis via the VAR model proposed earlier.

We report the impulse-response function (IRF) estimates of our financial market variables to the unexpected 1\%-point increase in Mr. Trump's probability of winning during the 2020 election campaign in Figure 2. Also, Figure 3 provides the IRF estimates of Biden's probability shock. ${ }^{7}$ We employ two lags $(p=2)$, chosen by the Bayesian Information Criteria (BIC) with a maximum of 6 lags. The IRF point estimates are accompanied by one standard deviation confidence bands that are obtained via 1,000 nonparametric bootstrap simulations.

\footnotetext{
${ }^{6}$ We set the smoothing parameter $(\lambda)$ at 1 million for our daily frequency data. Having $\lambda=0.5$ million yields similar results.

${ }^{7}$ Trump's probability does not necessarily move in the opposite direction of Biden's probability, because they are determined in two separate binary contracts.
} 
These IRF estimates are obtained using the recent 1-year long daily observations from September 23, 2019 to September 18, 2020. As can be seen in Figure 1, Mr. Biden's probability of winning has dramatically increased in March 2020, causing the IRF estimations from the full sample period to come with very wide confidence bands. Estimations with the post-March 2020 yielded similar problems due to lack of observations. ${ }^{8}$ Employing one-year-long observations, however, we were able to obtain reasonably compact confidence bands for the effects of the Biden probability shock. For fair comparisons, we report the IRF estimates to the Trump probability shock using the same sample period, although we also provide the full sample estimation results in Figure A2 in the appendix, which are qualitatively similar to the results in Figure 2.

\section{Figure 2 somewhere here}

One notable finding is that the Trump shock generates significant appreciations of both the Chinese Yuan and the Mexican Peso in the short run, followed by persistent and significantly negative (depreciations) responses of both currencies. In response to the Biden shock, the Yuan initially responds positively, although such positive responses last for less than two weeks followed by significant depreciations for about six weeks. The Peso responds to the Biden shock negatively from the beginning until the responses become insignificant in about 12 weeks.

Interestingly, the default probability in both countries declines on impact when the Trump probability shock occurs, while they both exhibit significantly positive initial responses to the Biden probability shock. Their intermediate to long-term responses are positive whichever shocks occur, meaning that market participants in these financial markets view both candidates as a threat to these countries. It should be noted that $\mathrm{MSCl}$ stock market indices provide similar signals in the market. That is, stock prices rise initially only to the Trump shock, whereas they both quickly decrease to a negative region, while the Biden shock yields bear markets from the beginning in both countries.

\footnotetext{
${ }^{8}$ Point estimates are qualitatively similar.
} 
Putting these all together, we may conjecture that Trump's candidacy may help stabilize the financial market in the short run, because an expected presidency of the incumbent candidate may lead to a lower likelihood of foreign or economic policy discontinuity, even though market participants' fundamental prospects will eventually override such effects. That is, in the long run, they seem to expect harmful macroeconomic effects on China and Mexico whoever wins the presidency in the United States in November 2020. Next, we investigate this possibility further by comparing the dynamic effects of presidential election poll shocks identified via the recent two elections.

\section{Figure 3 somewhere here}

\section{Incumbent Candidate vs. New Entrant Candidate}

This section compares our findings from the 2020 U.S. Presidential election with those from the 2016 election to further investigate how the responses to the incumbent shock compare those to the new entrant shock. For this purpose, we replicate the model of Beard, Kim, and Stern (2017) to estimate the IRFs of Mexico-related variables to the Trump shock during the 2016 presidential campaign when Mr. Trump fiercely attacked Mexico. In addition, we estimate the IRFs as the probability shock to Mrs. Hillary Clinton, who was the Democratic (incumbent) candidate to succeed then-president Obama.

In Figure 4, we report and compare the dynamic responses of the Mexican Peso to: (1) the Trump shock in 2020; (2) the Biden shock in 2020; (3) the Trump shock in 2016; (4) the Clinton shock in $2016 .{ }^{9}$ It is interesting to observe that, similar to the Biden shock, the Peso depreciates immediately in response to the Trump shock in his first election in 2016 when he was the new entrant candidate like Joe Biden in 2020. Responses to both the new entrant shocks are relatively short-lived compared with those to the incumbent

\footnotetext{
${ }^{9}$ The 2016 election sample period is June 16, 2015 to October 14, 2016. See Figure A4 in the appendix for the full IRFs with the one standard deviation confidence bands to the Clinton shock in 2016.
} 
Trump shock that shows a much slower and more persistent convergence rate towards zero. On the other hand, the Peso initially appreciates in response to the incumbent's (Trump in 2020 and Clinton in 2016) probability shock.

\section{Figure 4 somewhere here}

We next report the responses of the MSCI-Mexico to these shocks in Figure 5. As we mentioned previously, the Mexican stock market index responds positively in the short run to the incumbent's (Trump in 2020 and Clinton 2016) probability shock while it decreases in response to the new entrant's (Biden in 2020 and Trump in 2016) probability shock.

Interestingly, the MSCl-Mexico responds significantly positively (see Figure A3 in the appendix for the confidence bands) in about one week when the Trump shock occurs for the 2016 U.S. election data. This may reflect the negative responses (depreciations) of the Mexican Peso that strengthens Mexico's trade competitiveness. It might be puzzling, however, to observe substantially negative effects of other shocks on the MSCl-Mexico even though these shocks also caused the Peso to depreciate. For the probability shock of 2020 candidates, this may reflect market participants' observation of trade hawks in the Trump administration, which often created non-price trade barriers that weakens the expenditure switching effect through the changes in the terms of trade.

\section{Figure 5 somewhere here}

Lastly, we compare the IRF estimates to these shocks on Mexico's default probability in Figure 6. As in Biden's case, the default probability rises from the beginning when the Trump shock occurs when he was the new entrant candidate. On the other hand, the default probability declines on impact when the incumbent candidate's (Trump in 2020 and Clinton 2016) probability of winning increases, implying that the projected presidency of the incumbent might help stabilizing the financial market in the short run as the market 
participants expect policy continuity. Nonetheless, the Trump shock creates persistently elevated higher risk to Mexico in the long run.

\section{Figure 6 somewhere here}

\section{Concluding Remarks}

This paper investigates causal links of the expected presidency to the performance of related financial markets utilizing the wisdom of crowds formulated in a prediction market. Our findings strongly suggest that Donald Trump's hawkish agendas against China and Mexico are indeed translated into economic threats to these countries in the financial market.

Unexpected increases in Mr. Trump's probability of winning the 2020 election generate persistent and significantly negative long-term responses of the Chinese Yuan

and the Mexican Peso. In addition to bearish responses in the stock markets, the sovereign default probability also rises significantly in the long run in both countries. Mr. Biden's probability shock also yields results that reflect pessimistic prospects although the responses are relatively short-lived. That is, market participants seem to view both candidates pose a threat to China and Mexico, more strongly by the expected presidency of Trump.

Our findings also imply that the shock to the winning probability of an incumbent candidate, Trump in 2020 and Clinton in 2016, tends to stabilize financial markets in the short run, possibly reflecting a lower policy uncertainty. That is, the sovereign default probability negatively responds to these shocks on impact, although initial optimism is quickly dominated by the fundamental pessimism in both countries. 


\section{References}

Beard, T. Randolph, Hyeongwoo Kim, and Michael Stern (2017), "Is good news for Donald Trump bad news for the Peso?", Applied Economics Letters 24(19), 1363-1368.

Christiano, Lawrence J., Martin Eichenbaum, and Charles L. Evans (1999), “Monetary policy shocks: What have we learned and to what end?", Handbook of Macroeconomics Vol.1, 65-148.

Goodell, John W., Richard J. McGee, and Frank McGroarty (2020), “Election uncertainty, economic policy uncertainty and financial market uncertainty: A prediction market analysis," Journal of Banking \& Finance 110(C), 105684.

Herron, Michael C., James Lavin, Donald Cram, and Jay Silver (1999), "Measurement of political effects in the United States economy: A study of the 1992 presidential election," Economics and Politics 11(1), 51-81.

Kim, Hyeongwoo (2013), “Generalized impulse response analysis: General or extreme?”, Econo-Quantum, Revista De Economia Y Negocios 10 (2), 135-141.

Knight, Brian (2006), "Are policy platforms capitalized into equity prices? Evidence from the Bush/Gore 2000 presidential election," Journal of Public Economics 90, 751-773.

Pesaran, H. Hashem and Yongcheol Shin (1998), "Generalized impulse response analysis in linear multivariate models," Economics Letters 58 (1), 17-29.

Snowberg, Erik, Justin Wolfers, and Eric Zitzewitz (2007), "Partisan impacts on the economy: Evidence from prediction markets close elections," Quarterly Journal of Economics 122 (2), 807-829. 
Wagner, Alexander F., Richard J. Zeckhauser, and Alexandre Ziegler (2018), "Company stock price reactions to the 2016 election shock: Trump, taxes, and trade," Journal of Financial Economics 130(2), 428-451.

Wolfers, Justin and Eric Zitzewitz (2006a), "Prediction markets in theory and practice," NBER Working Papers 12083, National Bureau of Economic Research, Inc.

Wolfers, Justin and Eric Zitzewitz (2006b), "Interpreting prediction market prices as Probabilities," NBER Working Papers 12200, National Bureau of Economic Research, Inc. 


\section{Figure 1. Probability Data and Daily Frequency Macroeconomic Data}
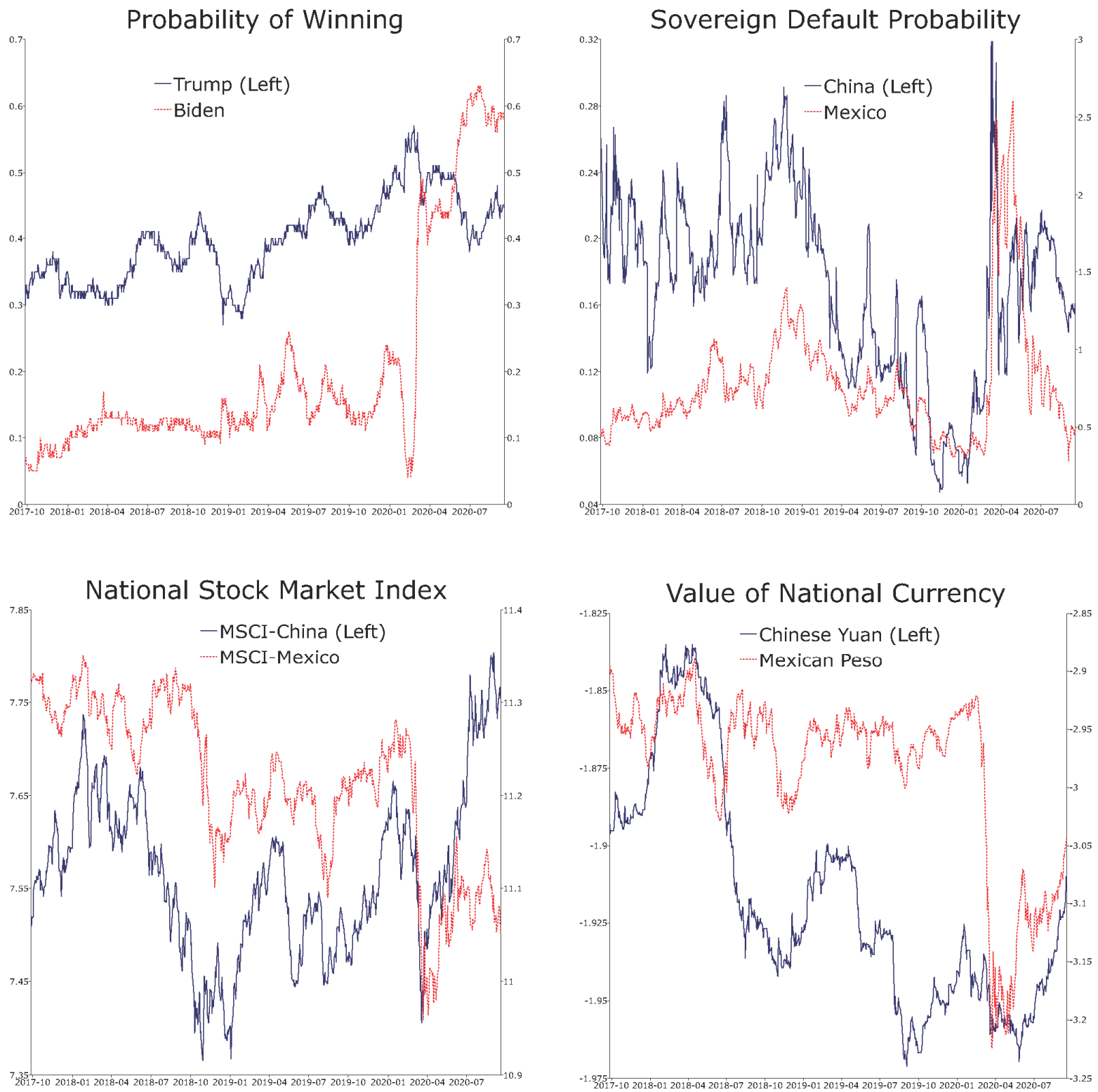

Note: Observations are daily and span from September 27, 2017 to September 18, 2020, excluding weekends (5 days per week). We obtained the probability of winning data from Predictlt.org. Authors calculated the sovereign default probability utilizing the credit default spread data for one-year sovereign bonds obtained from the Bloomberg terminal. We assumed $40 \%$ recovery rate in the zero-profit condition. We obtained national stock market indices from msci.com (Morgan Stanley Capital International), that is, $\mathrm{MSCl}-\mathrm{China}(\mathrm{CH} 50)$ and $\mathrm{MSCl}-\mathrm{Mexico}(\mathrm{MXMSCl})$. The values of the Chinese Yuan and the Mexican Peso in terms of the U.S. Dollar, are calculated using the exchange rate data from the FRED, DEXCHUS and DEXMXUS, respectively. National stock market indices and exchange rates are log-transformed. 


\section{Figure 2. Mr. Trump's Probability of Winning Shock}
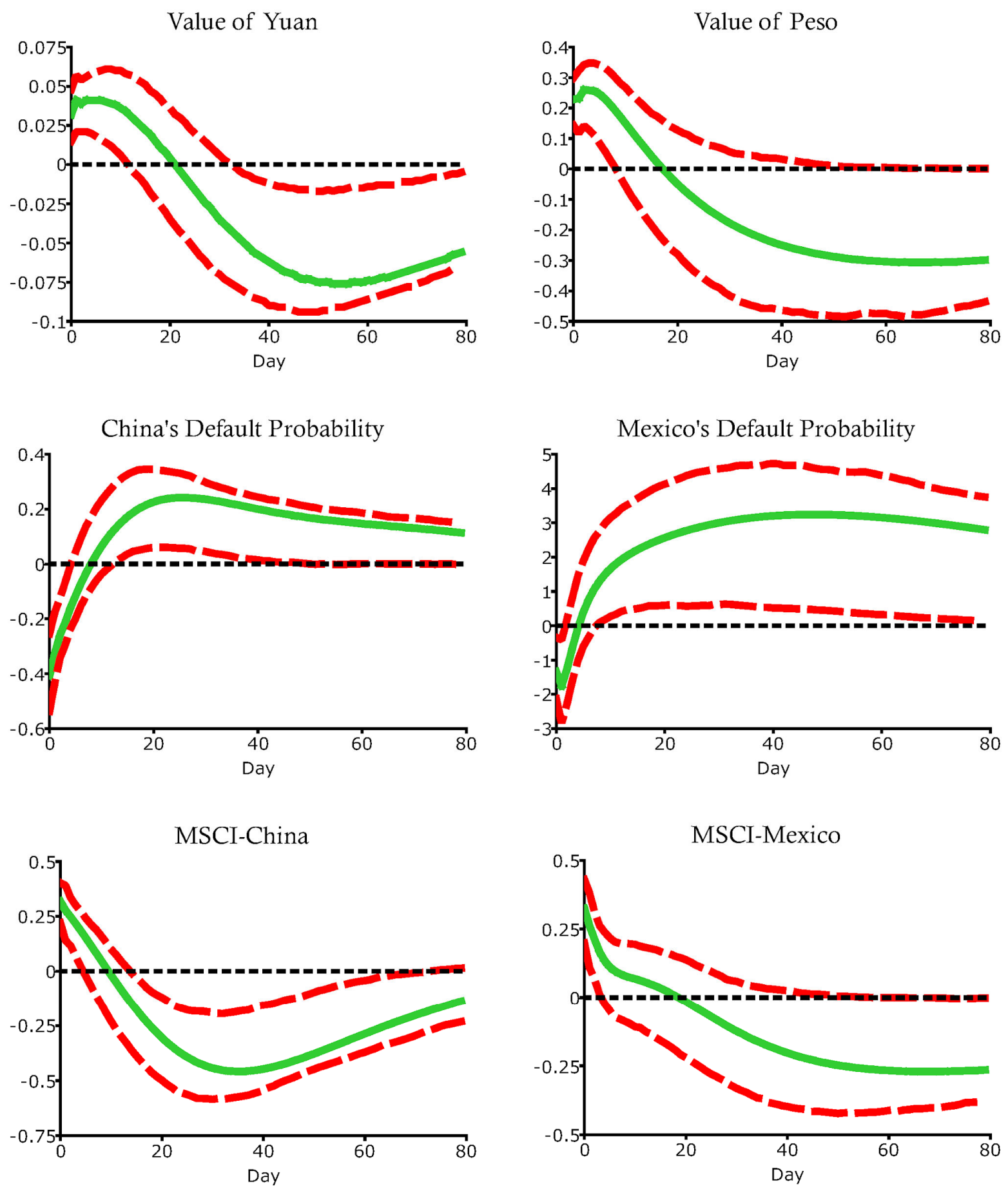

Note: We obtained the impulse-response function (IRF) to the 1\% Trump's probability of winning shock for the recent 1-year sample period from September 23, 2019 to September 18, 2020. We report the IRF point estimates (solid line) with one standard deviation confidence bands (dashed line) that are obtained from 1,000 nonparametric bootstrap simulations. Full sample (September 27, 2017 to September 18, 2020) results are qualitatively similar and reported in the appendix. 
Figure 3. Mr. Biden's Probability of Winning Shock
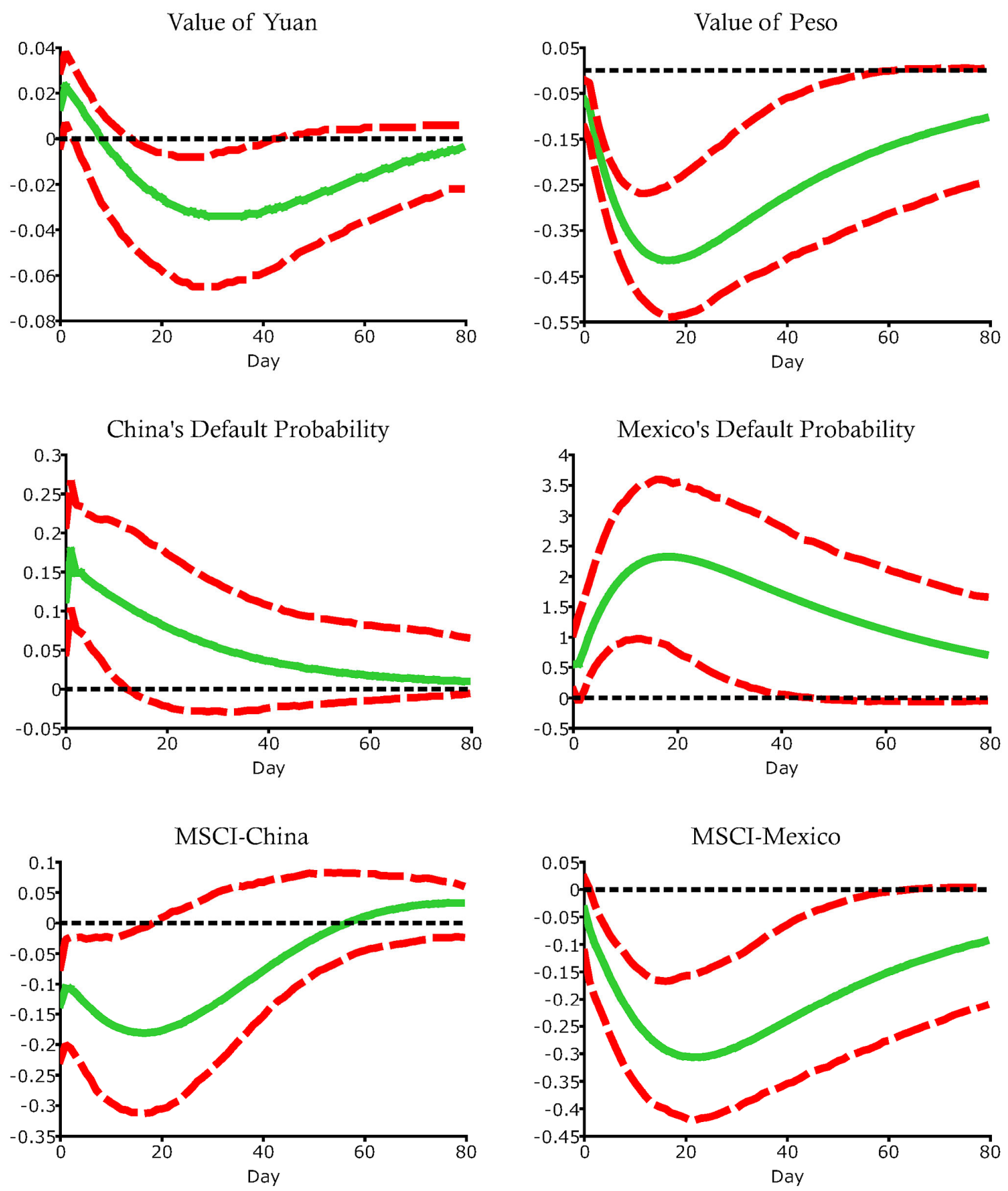

Note: Mr. Biden officially began his campaign on April 25, 2019, then was selected as the 2020 Democratic nominee in August 2020. Since his probability of winning dramatically increases in early 2020, estimating impulse-response functions (IRF) using the full sample tends to generate wide confidence bands. To obtain reasonably compact confidence intervals, we implemented the IRF estimations utilizing recent one-year long observations, September 23, 2019 to September 18, 2020. We report the IRF point estimates (solid line) with one standard deviation confidence bands (dashed line) that are obtained from 1,000 nonparametric bootstrap simulations. 
Figure 4. Probability Shock Effects on the Mexican Peso

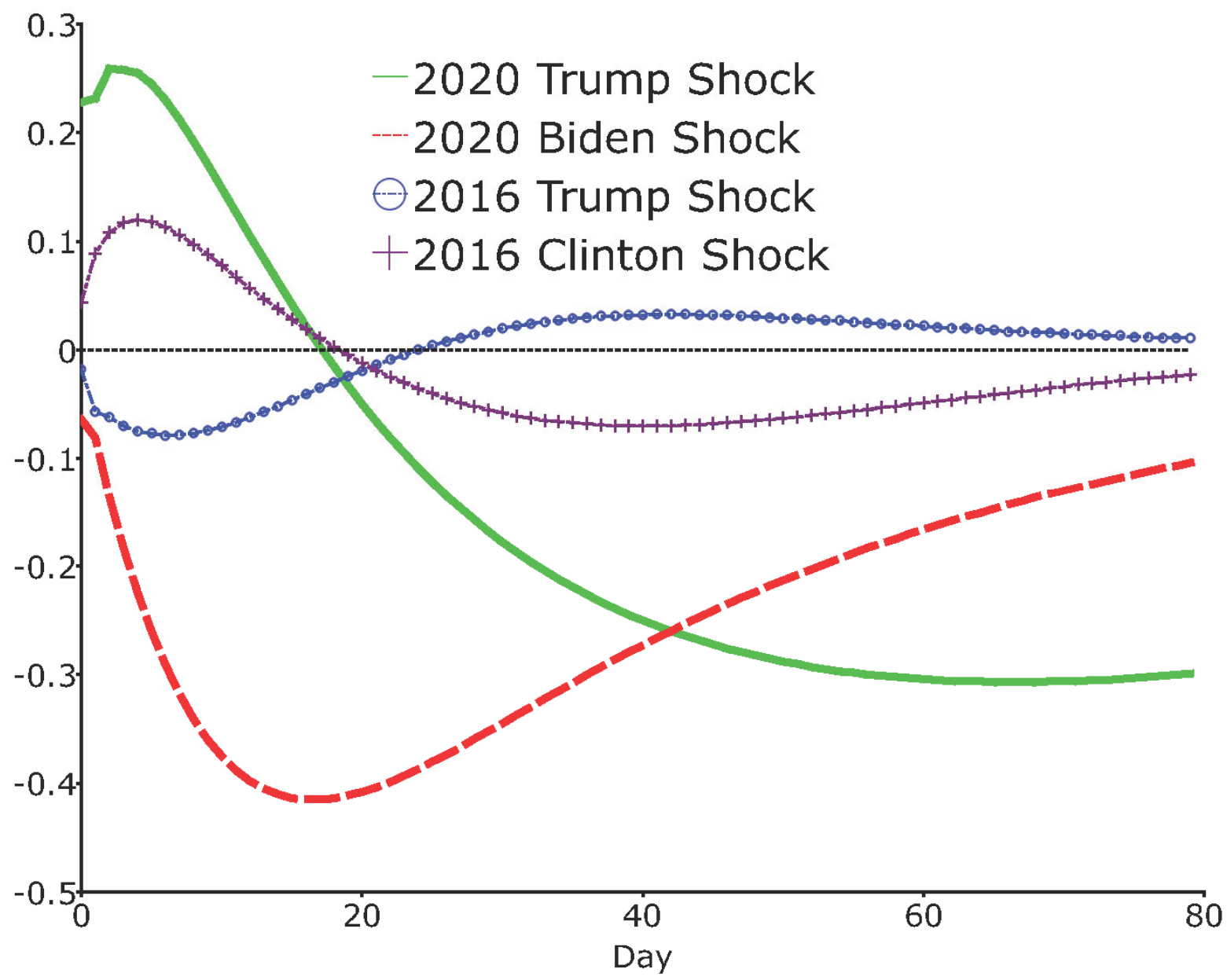

Note: We report 4 sets of the impulse-response function (IRF) estimates: (1) to $1 \%$ Trump's probability shock in 2020 (September 23, 2019 to September 18, 2020); (2) to 1\% Biden's probability shock in 2020 ; (3) to Trump's probability shock in 2016 (June 16, 2015 to October 14, 2016); (4) to Clinton's probability shock in 2016 (June 16, 2015 to October 14, 2016). 
Figure 5. Probability Shock Effects on Mexico's Stock Market Index

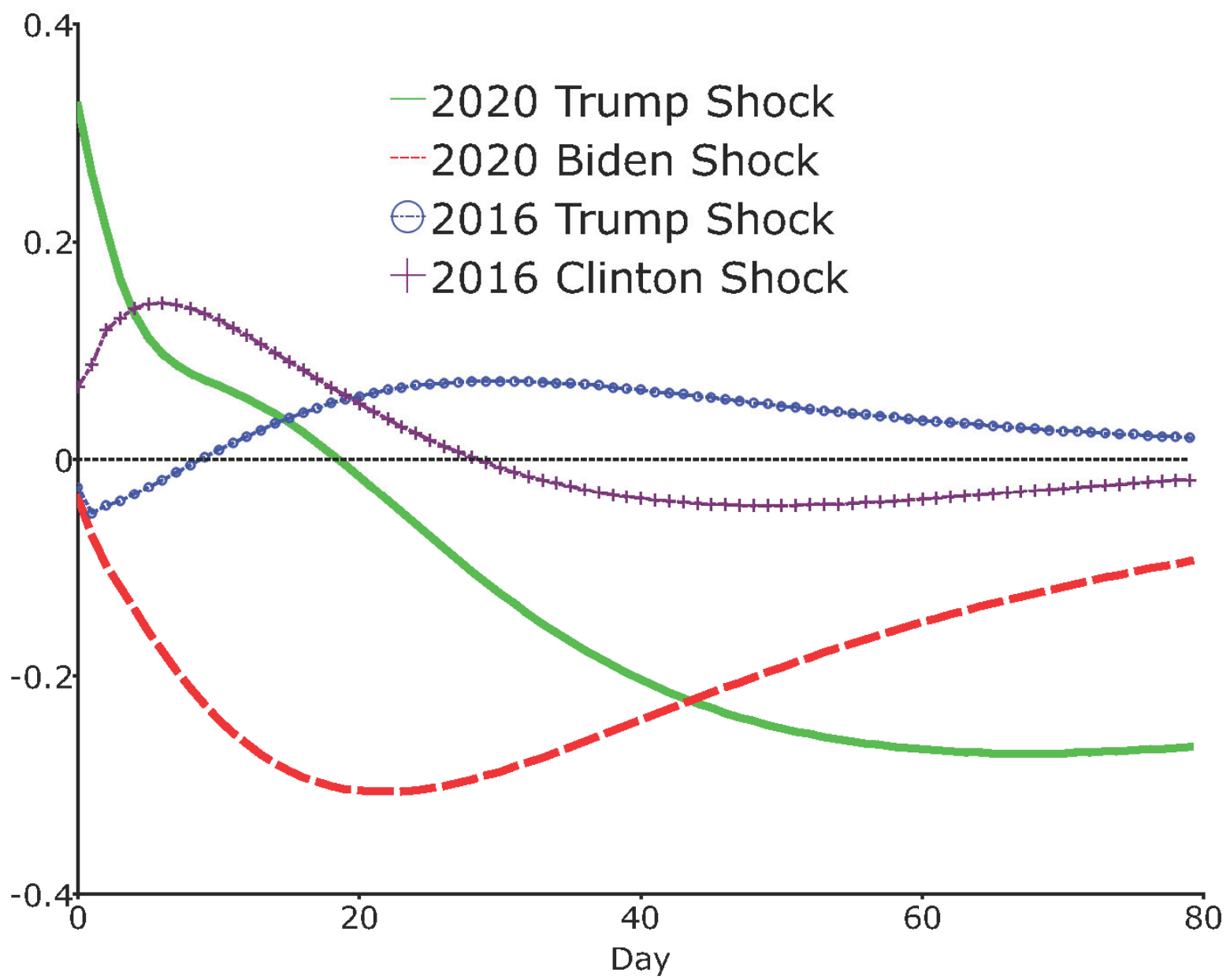

Note: Note: We report 4 sets of the impulse-response function (IRF) estimates: (1) to $1 \%$ Trump's probability shock in 2020 (September 23, 2019 to September 18, 2020); (2) to 1\% Biden's probability shock in 2020 (September 23, 2019 to September 18, 2020); (3) to Trump's probability shock in 2016 (June 16, 2015 to October 14, 2016); (4) to Clinton's probability shock in 2016 (June 16, 2015 to October 14, 2016). 
Figure 6. Probability Shock Effects on Mexico's Default Probability

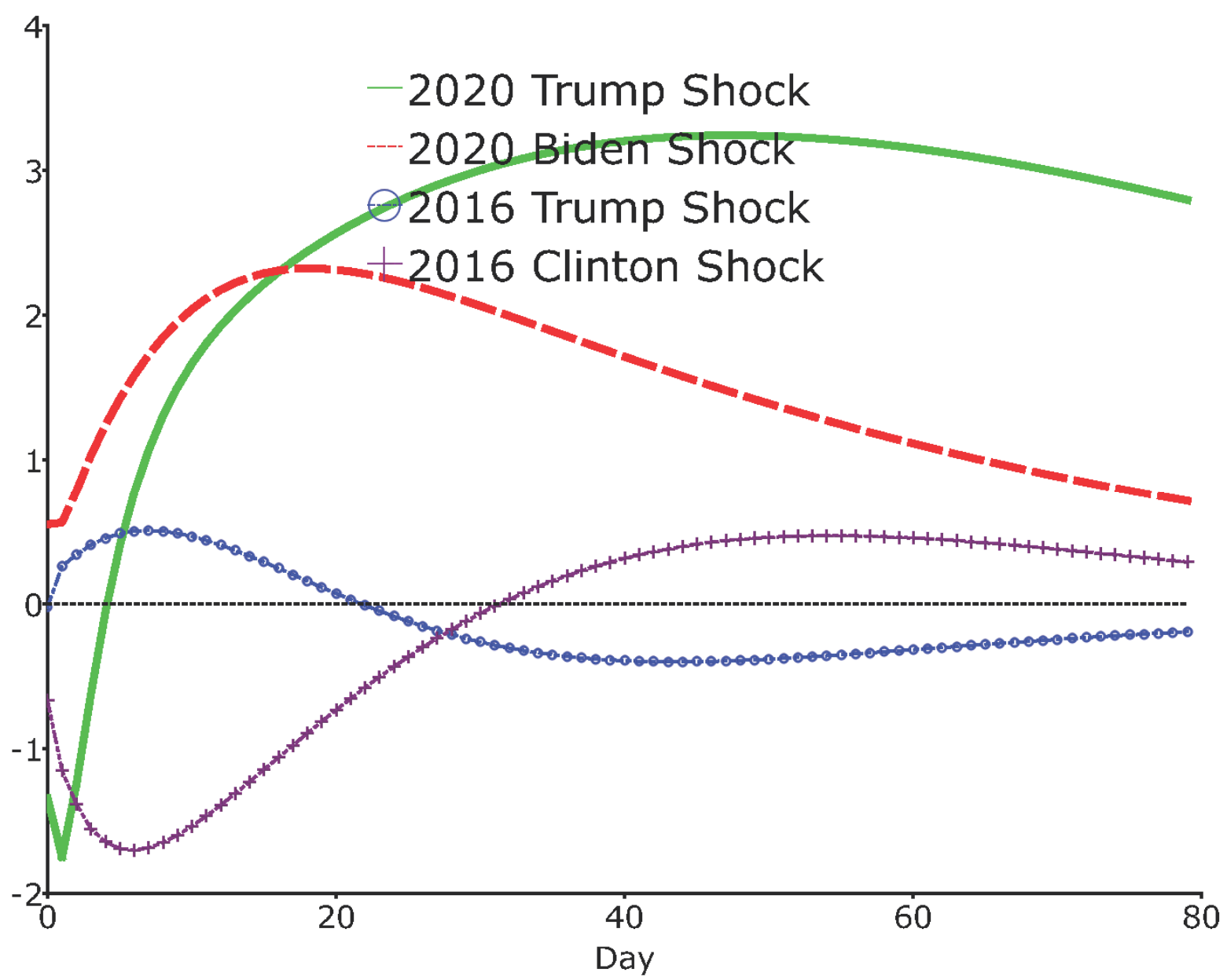

Note: Note: We report 4 sets of the impulse-response function (IRF) estimates: (1) to $1 \%$ Trump's probability shock in 2020 (September 23, 2019 to September 18, 2020); (2) to 1\% Biden's probability shock in 2020 (September 23, 2019 to September 18, 2020); (3) to Trump's probability shock in 2016 (June 16, 2015 to October 14, 2016); (4) to Clinton's probability shock in 2016 (June 16, 2015 to October 14, 2016). 


\section{NOt fOR PUblication APPENDIX}

Figure A1. Contemporaneous Relations of the Business Cycle Components
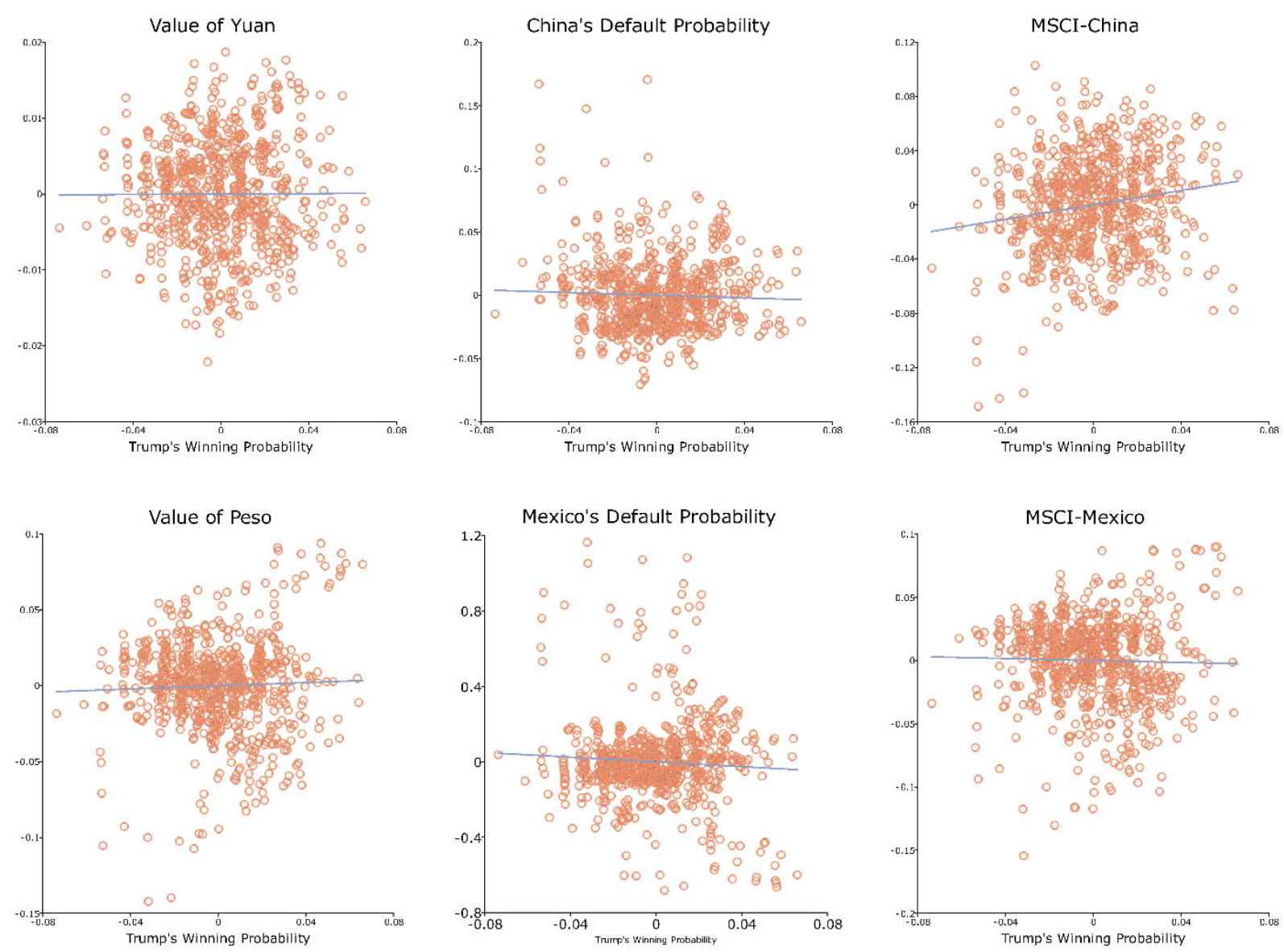

Note: The cyclical (business cycle) components are extracted via the Hodrick-Prescott (HP) filter with a smoothing parameter of 1,000,000 for daily frequency data. Scatter plots demonstrate the contemporaneous relationships between the Trump probability of winning vs. the other variables. The solid line is the least squares fitted line. 
Figure A2. Mr. Trump's Probability of Wining Shock: Full Sample Data
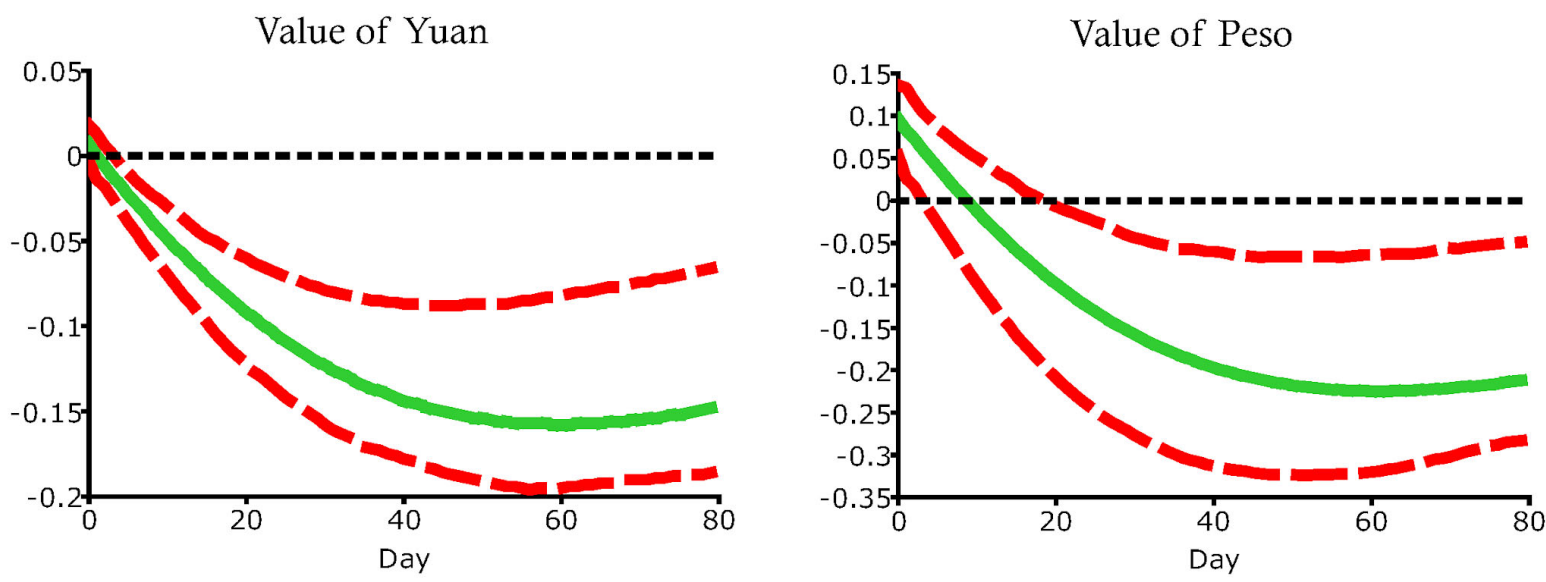

China's Default Probability

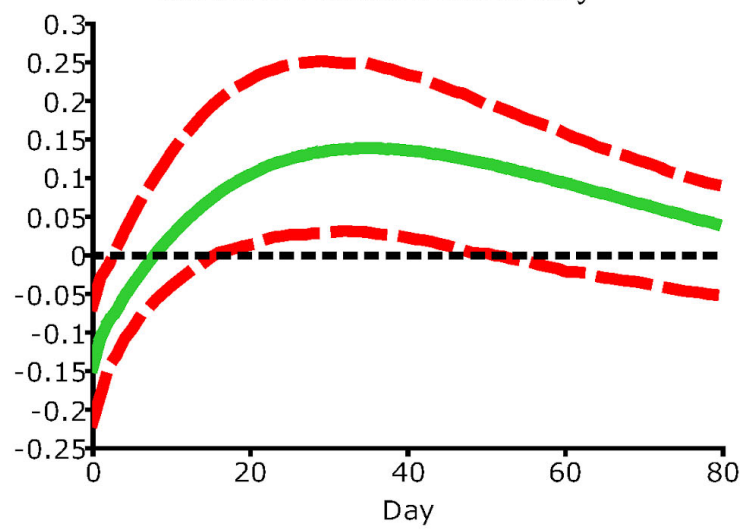

Mexico's Default Probability

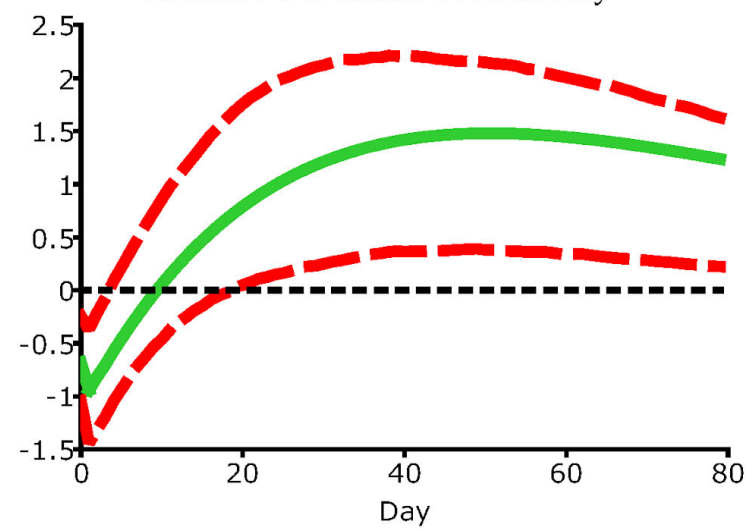

MSCI-China
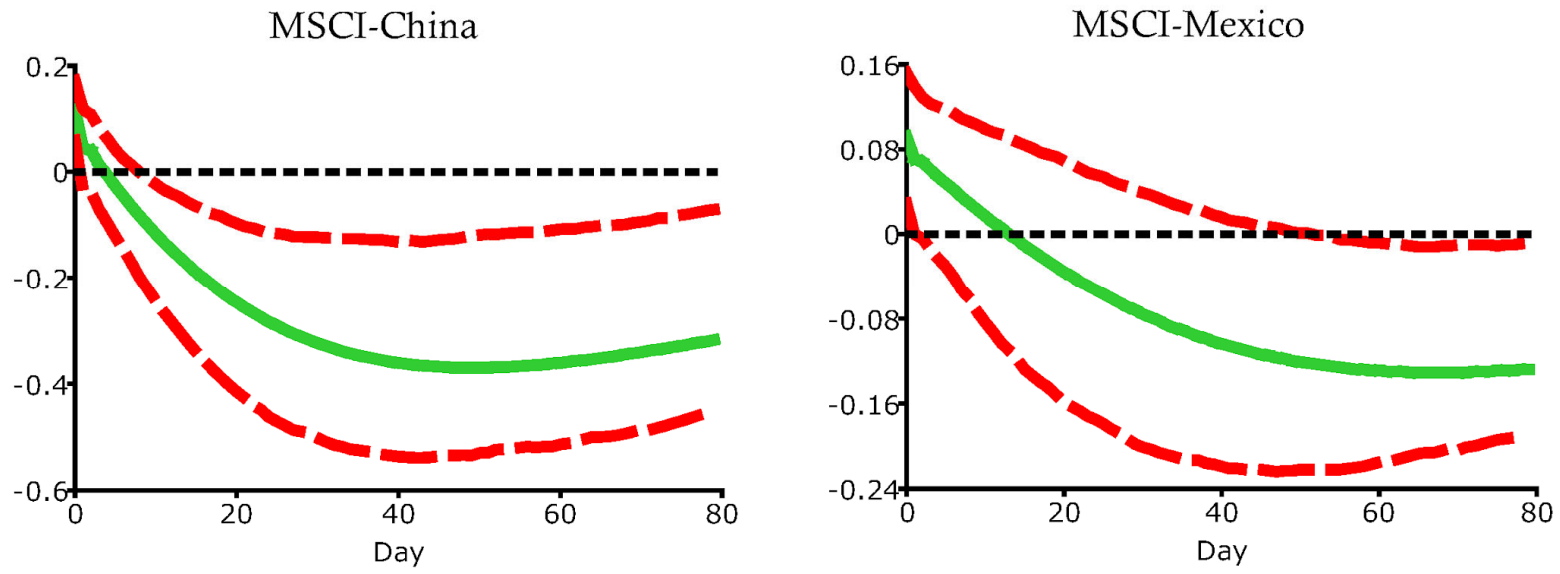

Note: We obtained the impulse-response function (IRF) estimates to the 1\% Trump's winning probability shock for the full sample period from September 27, 2017 to September 18, 2020. We report the IRF point estimates (solid line) with one standard deviation confidence bands (dashed line) that are obtained from 1,000 nonparametric bootstrap simulations. 
Figure A3. Mr. Trump's Probability of Wining Shock: 2016 Election Data
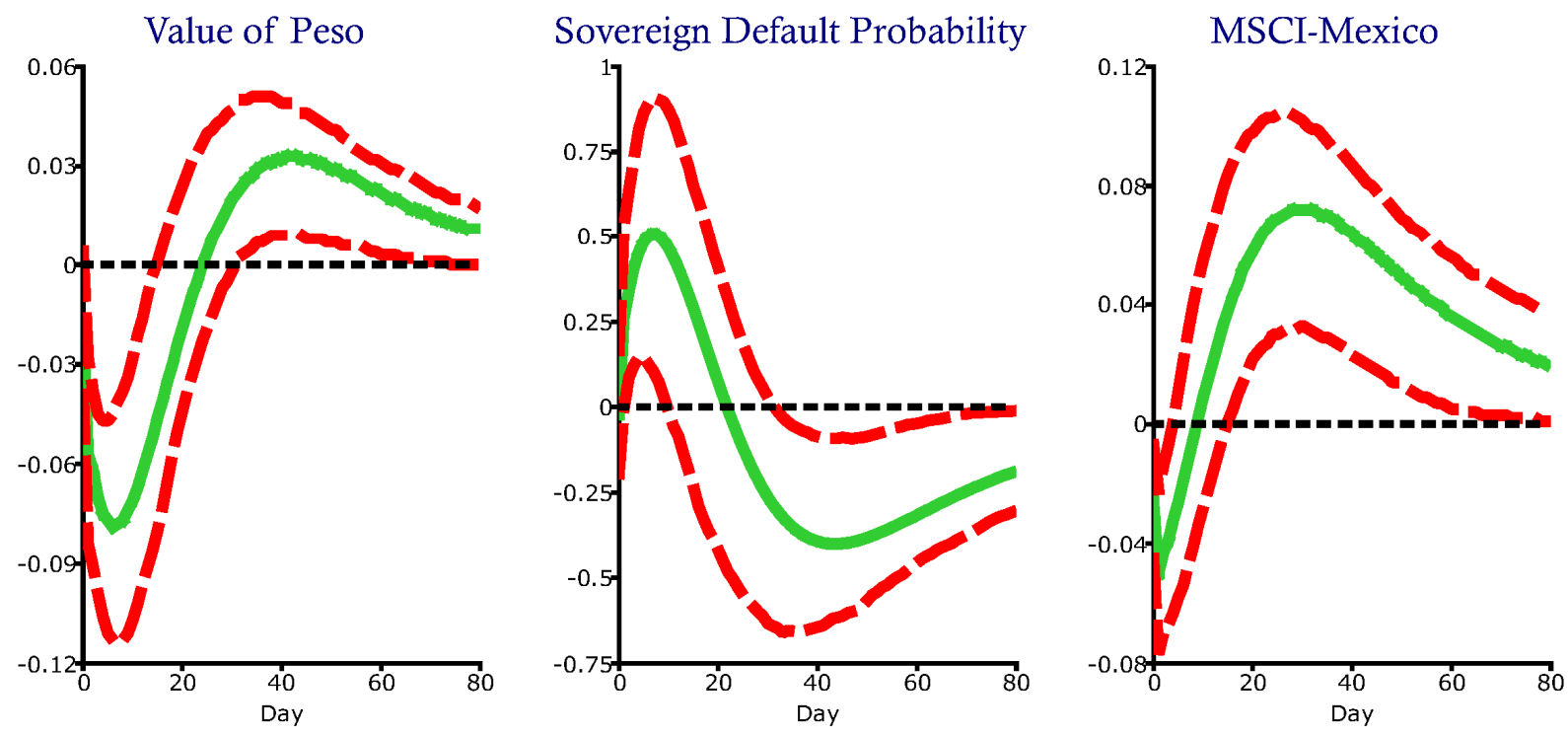

Note: We replicated the VAR results of Beard, Kim, and Stern (2017) that utilize daily frequency data from June 16, 2015 to October 14, 2016 during the 2016 presidential election campaign. Unlike them, we report the response of the value of the Peso instead of the value of the U.S. dollar in terms of the Mexican Peso. We report the impulse-response function point estimates (solid line) with one standard deviation confidence bands (dashed line) that are obtained from 1,000 nonparametric bootstrap simulations. 
Figure A4. Mrs. Clinton's Probability of Wining Shock: 2016 Election Data
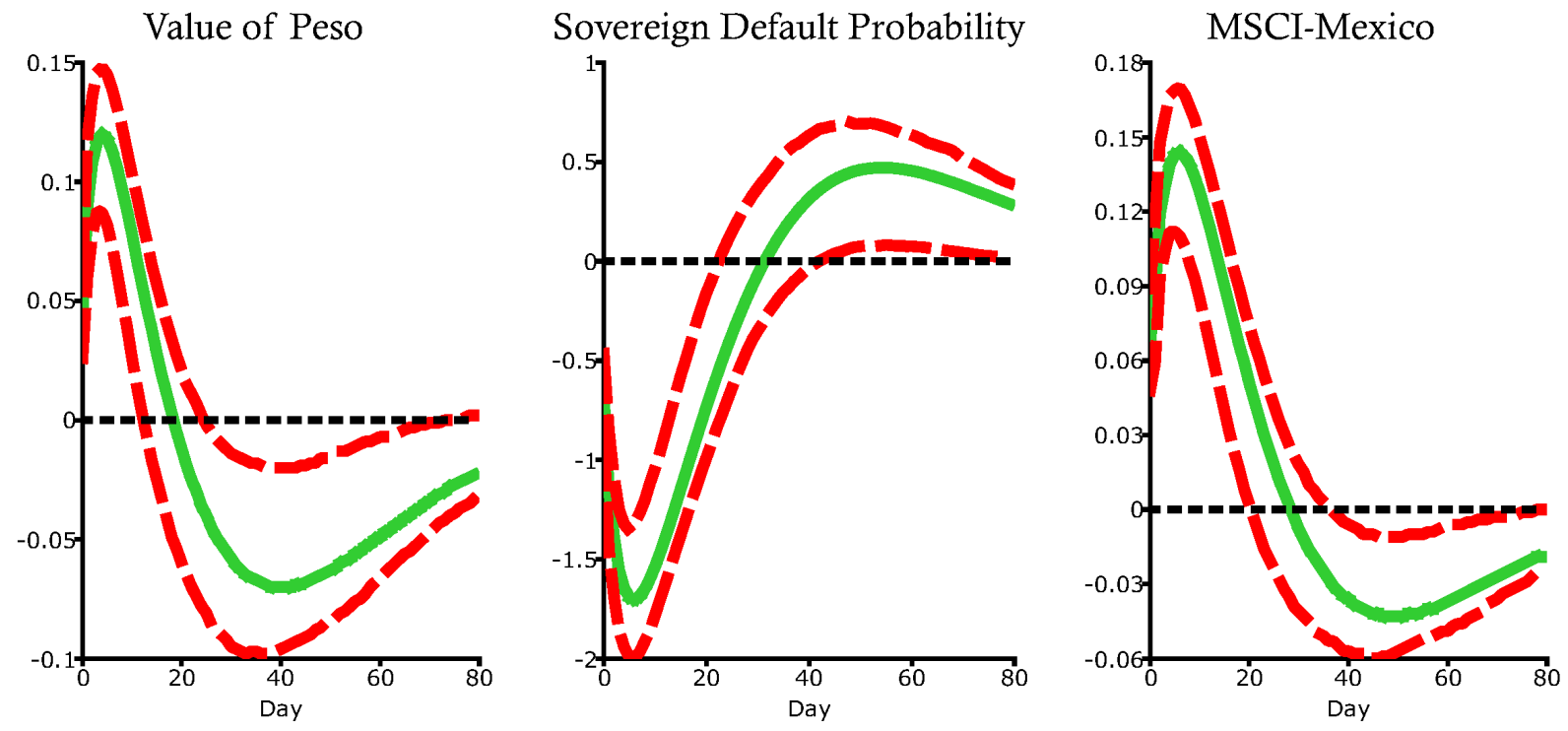

Note: We estimate the VAR model in Beard, Kim, and Stern (2017) for Clinton's probability shock that utilize daily frequency data from June 16, 2015 to October 14, 2016 during the 2016 presidential election campaign. We report the impulse-response function point estimates (solid line) with one standard deviation confidence bands (dashed line) that are obtained from 1,000 nonparametric bootstrap simulations. 